Análisis. Revista de investigación filosfófica, Vol. 1, $\mathrm{n}^{\circ}$ 1, 2014, pp. 41-67

\title{
YOU AND ME BABY AIN'T NOTHING BUT MAMMALS. SUBJECT NATURALISM AND DEFAULT POSITIONS ${ }^{1}$
}

\author{
María J. Frápolli
}

\begin{abstract}
RESUMEN
Este artículo discute el problema de la localización, tal como Price lo ha definido. En el se distinguen diferentes versiones de naturalismo y se defiende el naturalismo del sujeto. Se asume que el sistema de conceptos humano se ha desarrollado en interacción con el medio natural y social. Por esta razón no podemos evitar ser realistas y representacionalistas por defecto. Las afirmaciones básicas del realismo, el representatcionalismo y la teoría de la verdad como correspondencia son difícilmente rechazables, y esto explica el aire de artificiosidad que acompaña a las posiciones antirealistas. Sin embargo las posiciones por defecto no apoyan en absoluto a sus versiones filosóficamente desarrolladas. Estas son incompatibles con una visión naturalista sobre la realidad, el significado y la verdad.
\end{abstract}

PALABRAS CLAVE: Correspondentismo por defecto, naturalismo, naturalismo del sujeto, realismo por defecto, representacionalismo por defecto, teoría de la verdad como correspondencia, teoría prooracional de la verdad, verdad aristotélica

\section{ABSTRACT}

This paper deals with Price's placement problem. In it, different versions of naturalism are distinguished and subject naturalism is defended. It is assumed that human conceptual system has evolved as a result of humans relations with the natural

\footnotetext{
${ }^{1}$ My colleagues Manuel de Pinedo and Neftalí Villanueva have read versions of this paper and made insightful suggestions. I am also grateful to the Ministerio de Ciencia e Innovación del Gobierno de España, (project FFI2010-15704), the Consejería de Innovación de la Junta de Andalucía (project HUM-04099), and the Plan Propio of the University of Granada that have supported this work. My gratitude also goes to David Pérez Chico. Without his invitation, I probably would not have found the opportunity to work out the kind of naturalism with which I feel comfortable.
} 
and social surroundings. For this reason, we cannot but be realist and representationalist by default. The basis claims of realism, representationalism, and correspondence are hardly deniable, and this explains the artificiality scent that usually accompanies anti-realist positions. Nevertheless, the natural default positions do not lend any support to their philosophically implemented versions, metaphysical realism, semantic representationalism and full-blood correspondence. These approaches to reality, meaning and truth are incompatible with a sound naturalist stand on these issues.

KEYWORDS: Aristotelian truth, correspondence theory of truth, default realism, default representationalism, default correspondentism, naturalism, prosentential theory of truth, subject naturalism.

\section{NATURALISM, Which NATURALISM?}

Standard philosophical naturalism is the view that science matters to philosophy, or as Price puts it, "the view that natural science constrains philosophy" (2004, p. 71). The ways in which it matters or the features that science constrains might give rise to different kinds of naturalism, which are sometimes taken as (i) the claim that (good, respectable) philosophy melt into one of the natural sciences (Quine, 1981, p. 72), sometimes as (ii) the claim that philosophy is a continuum with sciences, and still some other times as (iii) the claim that the propositions that philosophy puts forward and the procedures it relies on have to be compatible with the content and methodologies of the sciences. Price calls (i) "object naturalism". For clarity I will dub it "reductionist object naturalism", and introduce "non-reductionist object naturalism" to cover (ii). Reductionist object naturalism aims at substituting one discipline (philosophy in general, epistemology, semantics, etc.) for another (physics, psychology, cognitive sciences, etc.). This implies that all concepts are in one way or another first-order empirical concepts, i.e., concepts that represent properties of physical objects. Non-reductionist object naturalism preserves an independent domain for philosophy. Both kinds constrain the topic and objects with which philosophy is allowed to deal, and if conflict arises, naturalism prescribes that philosophy should give way (since "science takes the lead", Price, 2004, p. 71). Although Quine has defended 
object naturalism in its two versions (Quine, loc. cit; Haack, 2009, p. 170 ff.), his name is linked with the reductionist kind thanks to his defence of empirical psychology as the scientific substitute for epistemology. Haack's foundherentism, on the other hand, which illustrates the structure of the web of knowledge by continuist metaphors such as the crossword puzzle and the map, is a case of non-reductionist object naturalism. She presents her alternative to the positivist model of the structure of knowledge as follows:

Rather than reduction, in the strong sense, there is integration of the social with the natural sciences. The Logical positivist's strong, simple, conception of the way all the truth about the world must fit together has obscured an otherwise obvious fact: heterogeneous truth are no less true, nor necessarily disjointed, for their heterogeneity. A better model might be a map in which a depiction of the roads, towns, etc., is superimposed on a delineation of the contours of the same territory." (Haack, 2007, p. 161)

And two years later, she writes:

The model is not, as a foundationalist's might be, how one determines the soundness or otherwise of a mathematical proof; it is, rather, how one determines the reasonableness or otherwise of entries in a crossword puzzle. This model is more hospitable to a gradational account. But the main motivation is that the crossword model permits pervasive mutual support, rather than, like the model of a mathematical proof, encouraging an essentially one-directional conception. (Haack, 2009, p.126)

Kind (iii) is naturalistic compatibilism, which has versions that fall under a liberal reading of object naturalism, but also admits interpretations close to Price's subject naturalism (2004, p. 73). The contention that philosophical propositions, or philosophical activity in general, should be compatible with the precepts of natural sciences implies that philosophy cannot lend support to ideas that directly or indirectly contradict the background and findings of other scientific disciplines. Incompatible ideas are, for instance, that human beings survive death, or that the future of people is written in the stars. Subject naturalism, in turn, indicates an attitude about us; it is a background position: if we humans belong to the natural world (and how could we not), the knowledge we claim to possess cannot require abilities that exceed our natural capabilities. Or more precisely, the ways to knowledge 
reclaimed by philosophy in order to sustain or justify its views cannot go beyond the kind of animal that science says we are. A declaration of subject naturalism is Peirce's opposition to Cartesianism, in "Some Consequences of Four Incapacities". According to Peirce,

1. We have no power of Introspection, but all knowledge of the internal world is derived by hypothetical reasoning from our knowledge of external facts.

2. We have no power of Intuition, but every cognition is determined logically by previous cognitions.

3. We have no power of thinking without signs.

4. We have no conception of the absolutely incognizable. (1868b, p. 140)

Thus, "certain Faculties claimed for Man" (see Peirce, 1868a) are not supported by scientific evidence. Against Cartesianism, which begins with universal doubt, and Scholasticism, which acknowledges absolute truths, Peirce advices "not pretend to doubt in philosophy what we do not doubt in our hearts" (loc. cit.); a conspicuous avowal of naturalism.

And now the next pair of labels: "object compatibilism", for the first type of compatibilism, and "subject compatibilism", for the second type. Compatibilism, in all its versions, is the aspiration of some coherentist approaches to knowledge. Object naturalism, on the other hand, is what lies beneath the standard versions of empiricist foundationalism.

I endorse subject compatibilism, and as I cannot see any difference between this position and Price's subject naturalism, I will adopt Price's label. Being a background position is right in declaring subject naturalism to be more fundamental than "its most popular contemporary manifestation" (2004, p. 72), object naturalism.

Besides object and subject types, naturalism can also be methodological: in the pursuit of its aims, philosophy should proceed as sciences do. Alleged methods of knowledge acquisition or justification procedures such as intuition or subjective, non-communicable certainty should be forbidden. Methodological naturalism also admits alternative versions: it can be seen either as an independent claim on the acceptability of justification methods, or as an aspect of subject naturalism. According to the different scientific theories, the animals we are acquire the knowledge and skills that have enabled our survival by routes that have proved to be evolutionary 
successful. If philosophy claims to produce knowledge, its ways of doing so need to be in accordance with those procedures that science has sanctioned as humanly suitable.

Needless to say, all these positions are artificially distinguished, and only vaguely characterized. Terms like "continuous" or "compatible" usually convey only intuitions and images. What does it mean that philosophy should be compatible with science? And more pointedly, how do we know? Besides, any naturalist could conceivably be classified under more than one of these labels. For instance, Haack also seems at times close to subject naturalism. "Still, we humans are animals", she claims in (2007, p. 156), and continues: "biological facts certainly constrain what social arrangements are humanly possible" (loc. cit.).

Nevertheless, the customary nonchalant use of labels such as "naturalism", "realism", "representationalism", and many others often leads debates that reach dead ends. It is thus crucial to show that the prevailing association between naturalism and scientific reductionisms is not unavoidable.

In the following pages I will elaborate on subject naturalism and isolate the intuitions on which naturalist and non-naturalist representationalism rest. I will argue that realism and representationalism are our positions by default. Metaphysical realism and semantic representationalism, their philosophically implemented versions, are nevertheless untenable both for philosophical and naturalistic reasons. Acknowledging the weaknesses of semantic representationalism does not require sophisticated, nonstandard stances on language; it suffices to pay attention to some basic intuitions, which I take to be empirical, stressed by some of the more prominent philosophers of language of the last century.

\section{THE ROOTS OF REPRESENTATIONALISM}

As Price characterizes the situation, standard naturalists, i.e. reductionist object naturalists, and their non-naturalist critics all share a semantic presupposition (2004, p. 72): a representationalist approach to meaning. Most proposals that have had any influence in the philosophy of language in the past century have been classified as representationalist, at least in their standard interpretations. If it were shown that the presupposition is groundless, the contenders on both sides of the debate would suffer the same fate, and be left without their semantic premise in one blow. The core of 
representationalism is the intuition that having a meaning is an issue of depicting state-of-affairs. The depiction can range from the most naive interpretation, as in some readings of Wittgenstein's Tractatus, to the sophisticated kind that supports Austin's definition of truth (Austin, 1950) or Situation Semantics (Barwise \& Perry, 1983 passim). Contemporary contextualism embraces representationalism as well, so that not in vain Recanati's approach to meaning is known as Truth Conditional Pragmatics (see Reacanati, 2010), in allusion to truth conditional semantics, which in its classical versions is a paradigm of representationalism. Strictly speaking, truth conditional semantics can be supported from representationalist as well as from non-representationalist accounts of language, but in the last century the representationalist interpretation has been dominant. All representationalist approaches assume that to say something is to identify an entity of which the speaker predicates a property. The two basic speech acts are thus referring to and describing. Asserting is then the combination of the two, referring-cumdescribing.

A powerful analogy that illustrates the representational intuitions that standard naturalists and non-naturalists have in common is Price's matching game:

Imagine a child's puzzle book, arranged like this. The left-hand page contains a large sheet of peel-off stickers, and the right-hand page shows a line drawing of a complex scene. For each sticker - the koala, the boomerang, the Sydney Opera House, and so on - the reader needs to find the unique outline in the drawing with the corresponding shape. The aim of the game is to place all the stickers in their correct locations, in this sense.

Now think of the right-hand page as the world, and the stickers as the collection of all the statements we take to be true of the world. For each such statement, it seems natural to ask what makes it true; what fact in the world has precisely the corresponding "shape". Within the scope of this simple but intuitive analogy, matching true statements to the world seems a lot like matching stickers to the line drawing. (Price, 2011, p. 3)

The matching game identifies saying, predicating, and referring. All of them entail the task of placing stickers in their matching shapes. The matching game illustrates the "placement problem" (Price, 2011, pp. 3-6).

Representationalism never walks alone. It systematically comes in packages that include other semantic positions together with a variety of 
metaphysical theses. Thus, when meaning is representing, truth becomes representational success. A sentence is true if, and only if, things are as depicted in the sentence. This is the basic claim of the theory of truth as correspondence. Representationalism and correspondence are steady companions. Austin's definition of truth leaves no doubt about the connections between representationalism and the correspondence theory of truth:

And finally (for present purposes-of-course there are other conditions to be satisfied too) there must be two sets of conventions: -

Descriptive conventions correlating the words (= sentences) with the types of situation, thing, event, etc., to be found in the world.

Demonstrative conventions correlating the words (= statements) with the historic situations, etc., to be found in the world.

A statement is said to be true when the historic state of affairs to which it is correlated by the demonstrative conventions (the one to which it "refers") is of a type with which the sentence used in making it is correlated by the descriptive conventions. (Austin, 1950, p. 5)

The connections here are so close that Strawson's main criticism against Austin's definition is that it has blurred the distinctions entirely (Strawson, 1950, p. 22).

Representationalism-cum-correspondence can be complemented to become either a naturalist or a non-naturalist general position, depending on the theses included in the package. A reductionist metaphysical thesis about what there is will convert representationalism-cum-correspondence into reductionist object naturalism. In these positions, truth applies only to sentences on the designated level, the level that so to say is in contact with the world (ordinary empirical discourse, the language of physics, the language of empirical psychology, or any other preferred alternative). The truth of sentences on other levels is derivative, and implies translation into sentences on the designated level. Radical empiricism is an example of reductionist object naturalism.

A non-naturalist extension of representationalism-cum-correspondence is metaphysical realism. Here, placement problems, those illustrated by Price's 
matching game, are solved by populating the world, by "engrossing" (as Price says, 2011, p. 3) the number of outlines on the right-hand page. Thus, if the outlines on the right-hand page are predetermined and essentially fewer in number than the stickers on the left-hand page, we play the reductionist (object naturalist) game. If, on the contrary, we are allowed to draw as many outlines as we need in order to use up all the stickers, we play the metaphysical realist game. Object naturalism thus presupposes a representational theory of meaning for those parcels of discourse that natural science and philosophy manage together, whereas realism implies universal representationalism covering assertive discourse in general.

Representationalism is the crux of the matter, as Price rightly stresses. Even philosophers that lead the pragmatic turn in the philosophy of language in the second half of the past century adhere to representationalism as their general theory of meaning. The famous dispute between Austin and Strawson on truth, mentioned above, exposes with disconcerting clarity the contradictions concealed in the representational kind of pragmatism that both authors profess. Strawson endorses Austin's representationalism while at the same time confronts him with the simplest and therefore maximally damaging version of the placement problem. Here are the two texts:

My central objection to Mr. Austin's thesis is this. He describes the conditions which must obtain if we are correctly to declare a statement true. His detailed description of these conditions is, with reservations, correct as far as it goes, though in several respects too narrow (Strawson, 1950, p. 22, my italics)

Consider the simplest of these cases, that involving negation. With what type of state-of-affairs (chunk of reality) is the sentence "The cat is not on the mat" correlated by conventions of description? With a mat simpliciter? With a dog on a mat? With a cat up a tree? The amendment of Mr. Austin's view to which one might be tempted for negative statements (i.e., "S is true" = "The state of affairs to which $\mathrm{S}$ is correlated by the demonstrative conventions is not of a type with which the affirmative form of $\mathrm{S}$ is correlated by the descriptive conventions") destroys the simplicity of the story by creating the need for a different sense of "true" when we discuss negative statements. (Strawson, 1950, p. 21).

In fact, the "amendment" which Strawson attributes to Austin shows that Austin's correspondentism is what I will call "default correspondentism". 
In this text, Strawson reminds Austin that not all kinds of statements can be analysed as involving demonstrative and descriptive conventions; that for negative, but also general, existential, hypothetical, and disjunctive sentences the account does not work (Strawson, 1950, p. 22). And Austin answers by diluting his view into a truism. Now, Austin should not need to be reminded. He is well aware of the non-descriptive role of some concepts when he claims:

It has come to be seen that many specially perplexing words embedded in apparently descriptive statements do not serve to indicate some specially odd additional feature in the reality reported, but to indicate (not to report) the circumstances in which the statement is made or reservations to which it is subject or the way in which it is to be taken and the like. To overlook these possibilities in the way once common is called the 'descriptive' fallacy; but perhaps this is not a good name, as 'descriptive' itself is special. Not all true or false statements are descriptions, and for this reason I prefer to use the word 'Constative'. Along these lines it has by now been shown piecemeal, or at least made to look likely, that many traditional philosophical perplexities have arisen through a mistake- the mistake of taking as straightforward statements of fact utterances which are either (in interesting non-grammatical ways) nonsensical or else intended as something quite different (Austin, 1962, p. 3).

This situation manifests that the roots of representationalism are deeper than what is explicitly recognized. At the same time, a representationalist approach to key topics in metaphysics, philosophy of language, and philosophy of logic, topics such as meaning, reference, truth, existence, and validity, has proved to be highly inoperative. Williams, for instance, declares that "[t]he view that this book is concerned to defend is that most of these theories and problems are the result of an inadequate appreciation of the way in which 'be', 'true, and 'same' work (Williams, 1992, p. ix). For the case of truth, see (Frápolli 2013, passim).

By rejecting representationalism, Price opposes object naturalism and non-naturalism alike (2004, p. 73 ), and proposes the following "Invalidity Thesis", [IT]:

[IT] "There are strong reasons for doubting whether object naturalism deserves to be 'validated' - whether its presuppositions do survive subject naturalist scrutiny" (Price, 2004, p. 74). 
Price stresses that subject naturalism does not support object naturalism, but rather the opposite. A conscious subject naturalist would understand object naturalism as undefendable.

I accept [IT] and reject representationalism altogether. However, given that representationalism is the first theory that comes to mind on beginning to think about meaning, then subject naturalism should offer an explanation of its pervasiveness. In the following sections I will argue that there is a coherent narrative that explains why representationalism is accepted so easily, a narrative that supports Price's intuition about the troublesome coexistence of subject and (reductionist) object kinds of naturalism.

\section{Default positions}

Humans cannot help being (default) realists, (default) representationalists and, given the structure and functioning of natural languages, (default) correspondentists. In what follows, I will argue that their philosophically implemented namesake cousins cannot grow from the presuppositions assumed by the default positions.

The physical world we have access to through the senses is an automatic assumption of natural creatures, not a conscious decision on our part. This is "default realism" (Frápolli, in press), and it is what should be expected if subject naturalism is taken seriously. Default realism is a spontaneous attitude, not a toy version of metaphysical realism with its theoretical assumptions reduced to a minimum. My belief that there is a computer in front of me, that my car is in the garage even if I cannot see it at this moment, that the scene (which I see from my office) of my son doing his homework in the living room is not a whimsical product of my mind, are not reached after any inferential process. We do not doubt these types of situations "in our hearts" (Peirce, loc. cit). Metaphysical realism is something else. It is the elaborate philosophical position that regards human beings in contrast with their natural environment, the view that distinguishes two antagonistic kinds of substances, res extensa and res cogitants, with irreconcilable properties and behaviour, and ruled by different sets of laws. It is the philosophical position that welcomes the sceptic to find the way between mind and world. If we humans had any justification to develop the extremely cautious attitude by which metaphysical realism deals with the experience of the external world and other minds, then our instinctive confidence concerning what we see and 
touch would be utterly irrational. Thus, whereas default realism is the natural attitude, the accommodation of metaphysical realism in the evolutionary history of our species is far from trivial. The default position is what Wittgenstein's aphorisms convey:

109. "An empirical proposition can be tested" (we say). But how? And through what?

110. What counts as its test? - "But is this an adequate test? And, if so, must it not be recognizable as such in logic?" - As if giving grounds did not come to an end sometime. But the end is not an ungrounded presupposition: it is an ungrounded way of acting (Wittgenstein, 1969)

Default realism cannot be proved, but it cannot be rejected, either. Nothing that can be said will settle the debate between metaphysical realism and the kind of pragmatism detectable in Wittgenstein's text. No argument can silence the sceptic definitively; for once we recognize metaphysical realism as a meaningful opponent, we get trapped in the fly bottle. Default realism explains why metaphysical realism is so engaging, even though default realism lends no support to metaphysical realism.

In a similar sense, there is default representationalism, which is the semantic face of default realism. It is the natural reaction that makes children say "mum" in front of their mothers, and "water" in front of transparent liquids. The basic speech acts described by Wittgenstein in the first paragraphs of Philosophical Investigations (see for instance $\ 1, \$ 6$, and $\$ 8$ ) illustrate the gist of the representational view. If one asks somebody to bring this block here, we cannot doubt at the same time that there is a block there and that the word "block" is somehow related to bricks. Wittgenstein's resource to the notion of language game in Philosophical Investigations (PI) is precisely a manner to insist in that this elementary behaviour fails to explain the functioning of language:

It is no more essential to the understanding of a proposition that one should imagine anything in connexion with it, than that one should make a sketch from it. (PI, \396)

Instead of "imaginability" one can also say here: representability by a particular method of representation. And such a representation may indeed safely point a way to further use of a sentence. On the other hand a picture may obtrude itself upon us and be of no use at all. (PI, \397). 
There is a multiplicity of language games that humans can play and refuse to play, we can play the philosophy game, or play chess, and we can play the ethics game or the political game. But not every decision is at hand; we cannot help playing the default realist game, since playing it is part of what being rational animals means. And the same happens with default representationalism: playing the representationalist game is a natural reaction related to specific speech acts with empirical content. The representational game loses its trivial aspect, however, as soon as we engage in speech acts with higher degrees of abstractness. Consider the following pair of sentences, uttered in appropriate contexts:

[1] Joan seeks his mobile phone in the car, and

[2] The European Community seeks peace in the Middle East.

Representationalism would diagnose that [1] and [2] admit an analogous semantic analysis, as they both depict state-of-affairs in a way or another. The perplexities prompted by the similarities and differences of [1] and [2] are well known. Benacerraf, for instance, examined them for the specific case of mathematical statements:

It is my contention that two quite distinct kinds of concerns have separately motivated accounts of the nature of mathematical truth: (1) the concern for having a homogeneous semantical theory in which semantics for the propositions of mathematics parallel the semantics for the rest of the language, and (2) the concern that the account of mathematical truth mesh with a reasonable epistemology. It will be my general thesis that almost all accounts of the concept of mathematical truth can be identified with serving one or another of these masters at the expense of the other. (Benacerraf 1973, 661)

The situation that Benacerraf explains remains unaltered if the focus is extended to non-empirical contents of any kind. The two horns of Benacerraf's dilemma for the case of abstract propositions such as [2] are (i) either maintaining the same semantic analysis that we commonly apply to [1] and then having to offer a nonstandard epistemic explanation concerning when 
and how [2] can be asserted, or (ii) offering a nonstandard semantic explanation of [2] that makes its epistemological treatment easier.

Focusing on practices explains the differences in behaviour of [1] and [2] and offers a way out of Benacerraf's dilemma. Practices are the bedrock facts. Option (i) would imply that the contents of [1] and [2] would perform similar communicative roles. Nevertheless, the circumstances in which we would be entitled to assert [1] are not the circumstances in which we would be entitled to assert [2]. Despite their grammatical similarities, a successful use of [1] will express a singular proposition that concerns physical entities, Joan, his mobile phone, and a car, whereas [2] will convey a general proposition with highly indirect connections with physical objects, if any. And the same happens with the consequences of the respective assertions. The commitments acquired by the utterance of [1] in the appropriate circumstances are not the commitments acquired by the agent of an act of asserting [2]. The stickermatching game is easier in the case of [1] than in the case of [2]. The application conditions of some assertions include reference to aspects of the surrounding nature. Meanwhile [1], used in appropriate contexts, might be explained by reference to physical objects, although much more theory is required to infer from this either that the content of assertive acts mirrors particular configurations of objects in the world, or that all concepts possess application conditions that relate them to particular physical objects or their properties. Assertions for which the application conditions are partly empirical possibly constitute the simplest kind of speech act, and they might have both chronological and logical priority in the development of language. This explains the prevalence of the representationalist approach, its default character, but it fails to justify representationalism as a general theory of meaning. Option (ii) would imply the lack of a unified account of language.

Representationalism and realism, in their philosophically developed versions, are dualist approaches in which mind and language contrast with something else, be it states-of-affairs, the world, reality or anything else. A naturalistic explanation of meaning should, on the other hand, integrate humans into their environment. To escape Benacerraf's dilemma, a nonreductionist position able to restore the unity of mind and world is required, a position capable of closing the gap that realists and representationalists alike insist on opening artificially. A pragmatist approach can do the job. 
The supply of pragmatism ${ }^{2}$ indispensable for a naturalist explanation of meaning includes acceptance of some basic principles that should not disturb any educated philosopher. One of these is the priority of assertion, [PA],

[PA] The simplest meaningful speech act is one in which agents put forward a propositional content that they endorse.

$[\mathrm{PA}]$ is detectable in all pragmatists. Brandom, for instance, is the latest philosopher to argue for assertions as language downtown (Brandom, 1994, p. 83), but [PA] has been a constant since Kant, at least. Also, [PA] stands at the origin of modern logic, as the Fregean Principle of Context shows: "Never to ask for the meaning of a word in isolation, but only in the context of a proposition (see Frege 1884, Introduction, p. x).

A second intuition that weighs pragmatism against representationalism is the way in which propositions are individuated. The representationalist method brings in the placement problem, the problem illustrated by Price's matching game, in full, since it individuates propositions according to the stateof-affairs (ingredients-plus-configuration) that they mirror. An alternative consists of individuating them by the role they perform connecting some acts with some others: the content of an act of assertion is identified by the inferences that go from the entitlements an agent has to possess in order to successfully perform it and the consequences to which the agent gets committed by the performance. "The link between pragmatic significance and inferential content", Brandom says, "is supplied by the fact that asserting a sentence is implicitly undertaking a commitment to the correctness of the material inference from its circumstances to its consequences of application" (Brandom, 2000, p. 63). And explains that "the content to which one is committed by using the concept or expression may be represented by the inference one implicitly endorses by such use, the inference, namely, from the circumstances of appropriate employment to the appropriate consequences of such employment" (Brandom, 2000, p. 62). Different sets of entitlements and

\footnotetext{
2 Pragmatism turns into pragmatics when applied to the theory of meaning. An approach is pragmatic, in the technical sense of the philosophy of language, if it makes room to contextual factors in the characterization of meaning. I will not distinguish between pragmatism and pragmatics, as my argument in this paper does not require it. I consider pragmatism the view that takes communicative practices as both the ultimate bedrock for any theoretical work on language and also the phenomena to be explained.
} 
commitments characterize different kinds of contents, some of them with empirical conditions and some others without them. Inferences do not require "placements"; they are moves in the continuous activity that comprises humans' communicative behaviour. This Brandomian terminology should not obscure the triviality of the claim, which implies that the content of a concept such as "wet" includes among its application conditions its connection to wet things. But this is not enough. In order to attribute to an agent the possession of the concept, one has to be sure that the agent understands the inferential relations between it and other concepts such humid (implication) and dry (incompatibility). Let us call this intuition, Minimal Inferentialism [MI],

[MI] Possessing a concept means to be able to apply it in successful speech acts and to draw some elemental consequences from its application.

The question of whether concepts such as value, meaning, or truth can or cannot be explained within naturalism is. from the viewpoint of subject naturalism, nonsense (of course, they can, how could they not?). If by using those concepts we humans perform actions that are recognizable by other humans, with an effect in communication and an identifiable function, then these concepts are by definition suitable for a naturalist treatment. Pragmatism has to explain how these concepts work in a natural system of concepts but not whether they work. The difficulty for the theorist is to offer an explanation that does not defy our nature as social animals. And the answer has to proceed by looking at the kind of actions in which the concepts concerned are put to work. Meanings are accounted for by appealing to the practices in which agents are involved when they use particular concepts, by their use of particular concepts or because they have used particular concepts. These practices typically relate agents to other agents and their surroundings and are describable in public, naturalistic terms.

\section{ARISTOTELIAN TRUTH}

Finally, there is also default correspondentism. Aristotle famously declared that "to say of what is that it is not, or of what is not that it is, is false, while to say of what is that it is, and of what is not that it is not, is true" (Metaphysics 1011b25). Since then, most proponents of theories of truth have 
vindicated Aristotle's words as their inspiration; Tarski (1944, §1.3) and Ramsey (1927/1991, p. 11) are examples. The Aristotelian dictum has been systematically interpreted as a declaration of correspondentism: if we are willing to agree with Aristotle's view on truth, then we most probably support a theory of truth as correspondence. But as it happens with default brands of realism and representationalism, default correspondentism, i.e. the Aristotelian view [AV], can be endorsed without adopting any commitment to a full-blown theory of truth as correspondence. This claim should be obvious from the fact that unsurmountable divergences arise as soon as philosophers try to develop their particular versions of [AV], which can be stated as follows:

[AV] To say the truth is to say of what it is that it is.

A semi-formal, more perspicuous version is $[\mathrm{AV}]_{\text {semi-formal }}$,

$[\mathrm{AV}]_{\text {semi-formal }}$ To say the truth is to say $\mathrm{p}$ when $\mathrm{p}$.

How could anyone reject that $\mathrm{p}$, when $\mathrm{p}$ ? [AV] expresses a grammatical truism that cannot be denied on pain of inconsistency. Expressions such as "it is true", "the truth", "how things are", "the facts", "it is so", "it is a fact", and many others are intra-linguistic resources to point to and pack together pieces of information, that range from singular propositions to the potentially infinite amount encoded by a theory (see Frapolli, 2013, ch. 3). These are schemas, as Wittgenstein explains in PI:

Let us examine the proposition ("Satz") 3: "This is how things are." - How can I say that this is the general form of the proposition? - It is first and foremost itself a proposition, an English sentence, for it has a subject and a predicate. But how is this sentence applied - that is, in our everyday language? For I got it from there and nowhere else.

We may say, e.g.: "He explained his position to me, said that this was how things were, and that therefore he needed an advance". So far, then, one can say that that sentence stands for any statement. It is employed as a propositional schema, but only because it has the construction of an English sentence. It would be possible to say instead "such and such is the case", "this

\footnotetext{
${ }^{3}$ Here "Satz" means sentence. We reserve the term "proposition" for the contents of some sentences in assertive speech acts.
} 
is the situation", and so on. It would also be possible here simple to use a letter, a variable, as in symbolic logic. But no one is going to call the letter "p" the general form of propositions. To repeat: "This is how things are" had that position only because it is itself what one calls an English sentence. But though it is a proposition, still it gets employed as a propositional variable. To say that this proposition agrees (or does not agree) with reality would be obvious nonsense. Thus it illustrates the fact that one feature of our concept of a proposition is, sounding like a proposition (IP\134).

The entities referred to by expressions such as "the facts" and "the truth" or the contents expressed by sentences such as "this is how things are" are propositions, i.e. conceptual complexes. Strawson clearly understood their role:

Facts are known, stated, learnt, forgotten, overlooked, commented on, communicated or noticed. (Each of these verbs may be followed by a "that"clause or a "the fact that"-clause.) Facts are what statements (when true) state; they are not what statements are about $(1950$, p. 7$)$

Verbs that admit that-clauses codify concepts whose arguments are or include concepts. This does not preclude those verbs from occurring in constructions with a singular term as the subject. Both "this is a fact" and "this is a car" are correct English sentences, but in spite of the obvious surface similarities, "this" in each case performs a markedly different role. If an interlocutor replied "which car?" surely the answer should be different from the answer one would give if asked "which fact?". In this latter case, the response must offer a propositional content: the fact that right-wing politics have led Southern European countries to bankruptcy. What statements convey are propositions, while propositions we endorse we call "facts". "Is a fact" is then a predicate of propositional contents, of entities capable of bearing a truth-value. Frege supports this position in Begriffsschrift.

We can imagine a language in which the proposition "Archimedes perished at the capture of Syracuse" would be expressed thus: "The violent death of Archimedes at the capture of Syracuse is a fact". To be sure, one can distinguish between subject and predicate here, too, if one wishes to do so, but the subject contains the whole content, and the predicate serves only to 
turn the content into a judgement. Such a language would have only a single predicate for all judgements, namely, "is a fact". We see that there cannot be any suggestion here of subject and predicate in the ordinary sense. Our ideography is a language of this sort, and in it the sign $F$ is the common predicate for all judgements. (Frege, 1879, pp. 12-3)

That expressions such as "is true" and "is a fact" perform the same function do not impede them from presenting stylistic deviations. This is something that Strawson also knew:

It would indeed be wrong - but not for Mr. Austin's reasons - to identify "fact" and "true statement"; for these expressions have different roles in our language, as can be seen by the experiment of trying to interchange them in context. Nevertheless their roles - or those of related expressions - overlap. There is no nuance, except of style, between "That's true" and "That's a fact"; nor between "Is it true that...?" and "Is it a fact that...?" (Strawson, 1950, p. 7)

Formal discrepancies between "true" and "fact" sustain those positions that see them as expressing distinguishable concepts and thus see their combination as explicative. It is advisable, in these cases, not to confuse terms with their contents. Consider the following pair of sentences, [3] and [4],

[3] That Archimedes died at the capture of Syracuse is a fact,

[4] "Archimedes perished at the capture of Syracuse" expresses a true proposition.

Both are well-formed English sentences. If we exchange the occurrences of "a fact" and "expresses a true proposition" in them, the result will be the strange sentences, [5] and [6],

[5] That Archimedes died at the capture of Syracuse expresses a true proposition,

[6] "Archimedes perished at the capture of Syracuse" is a fact.

Quotation marks are a linguistic convention for mention; when they are used, expressions, and not their contents, are highlighted. By means of expressions, agents express propositional and non-propositional contents. 
"Fact", on the other hand, makes no reference to expressions but rather help to endorse propositions, and hence the awkward effect that their combination produces. "That", in turn, is a device for propositional designation; it introduces propositions which are abstract entities, the contents of what is said, assumed, rejected, doubted, etc. and the bearers of logical properties, implication, and incompatibility. Expressions transmit contents and are linguistic entities with syntactic and semantic properties but without logical properties. This explains that the combination of "expresses" and "that" produces interferences due to their different range of application. Thus, even though "truth" and "fact" perform the same logical role, their occurrence together with other linguistic and conceptual tools not always produce the same results from the standpoint of linguistic correctness. "Fact" and "true" express the same conceptual device, both apply to propositions that the agent endorses and both are means to deal with indeterminate amounts of information as a whole. Syntactically, they are used to convert designations of propositions, i.e. singular terms that denote propositions, into complete sentences that express - in an appropriate context - those propositions. It is a denominalizer (Horwich, 1998, p. 5). To maintain the terminological symmetry, we could then consider quotation marks and terms such as "that", "the proposition that", and the like as nominalizers, i.e., functions whose arguments are expressions of propositions and whose values are designations of them. Putting the two functions together in an equivalence sentence, as typically occurs in the standard formulations of the theory of truth as correspondence, only gives rise to analytic sentences. The position on truth that derives from these grammatical remarks is "Default Correspondentism", a standard formulation of which is [DC],

[DC] Something is true if, and only if, it is a fact.

[DC] is analytically true and neither implies nor supports its metaphysically inflated versions. Being analytic, nothing substantive can follow from it.

The standard formulations of correspondence, [DC] among them, are somewhat tricky. "Something" and "it" are variables, proforms, anaphorically linked. Depending on their substitution instances, [DC] will produce either trivial grammatical remarks or weird combinations such as [7], [8], [9] and [10], 
[7] A sentence is true if, and only if, it is a fact,

[8] An event is true if, and only if, it is a fact,

[9] A proposition is true if, and only if, it is a fact,

[10] A state-of-affairs is true if, and only if, it is a fact.

It sounds odd to say that sentences are facts. With propositions, the equivalence is easier to accept in one direction (If a proposition is true then it is a fact) and sounds nonsensical in the converse (If a proposition is a fact then it is true). Events or states-of-affairs are meant to be physical complexes, whereas truth is said of abstract entities. In [DC] the terms "something" and "it" are indeterminate enough to allow (and hide) some kind of equivocation and thus, some of its instances - [7] -[10] for example — display category mistakes: true sentences do not fall within the application domain of "is a fact", events cannot be said to be true or false, etc. More acceptable are the following sentences, [11] and [12],

[11] True sentences express facts,

[12] True propositions are facts,

In any case, as variations on instances of [DC], [11]-[12] are as empty as their weird cousins [7]-[10] are.

If [DC] represents the grain of truth that lends support to the different versions of correspondence theories, [12] displays the correct intuition that supports identity theories of truth. Nevertheless, neither correspondence nor identity theories of truth gain ground on their own accord. They are both elaborations of correct, although merely grammatical, intuitions to which the proponents of these positions ascribe a theoretical weight that they do not possess.

In short, the appeal of correspondentist claims, such as the Aristotelian dictum, has a simple explanation: it depends on certain grammatical features of natural languages. Particularly, it derives from the job of locutions such as "it is a fact" and "it is true" as complex propositional variables. Phrases such as "it is true", "you are right" or "it is a fact" are the kind of linguistic tool that agents use to indirectly assert and endorse propositional contents. The conjoint occurrence of "true" and "fact" in sentences such as [11] and [12] transmits the impression that the sentence cannot be used to say anything false. The 
impression is correct, but the reason is not that they convey substantive necessary truths but rather that they lack any content whatsoever. [DC] makes only a grammatical remark that cannot give support to any significant metaphysical position.

As in the cases of representationalism and realism, here too a perfectly trivial assumption is mistakenly interpreted as a solid philosophical position. From default correspondentism, nothing substantial follows about the alleged relationship between words and the world. In particular, it follows neither that truth is a relation, nor that true sentences share with portions of the world, their alleged truth-makers, their structure or configuration.

A naturalist understanding of human beings is not jeopardized by these default positions. Default realism and default representationalism derive from subject naturalism, from what science says we are and how:we have evolved. Default correspondentism derives from the way in which our conceptual system, reflected in natural languages, has developed.

\section{EXISTENCE, OBJECTIVITY, AND THE PLACEMENT PROBLEM}

The placement problem derives from representationalism, as Price points out. But representationalism is not its only cause. Two systematic conceptual conflations add confusion to the topic: the first one is the identification of existence with spatiotemporal location; and the second one is the understanding of objectivity as some kind of externality to the mind. Somehow the two notions, existence and objectivity, boil down to some kind of placement out-from-the-subject's-mind. These two identifications are generalized, even though philosophers of logic and of language adhere without the slightest hesitation to the Fregean interpretation of numbers and quantifiers. And yet Frege's position is clear:

But, it will perhaps be objected, even if the Earth is really not imaginable; it is at any rate an external thing, occupying a definite place; but where is the number 4? It is neither outside us not within us. And, taking those words in their spatial sense, that is quite correct. To give spatial co-ordinates for the number 4 makes no sense; but the only conclusion to be drawn from that is, that 4 is not a spatial object, not that it is not an object at all. Not every object has a place. Even our ideas are in this sense not within us (beneath our skin); beneath the skin are nerve-ganglia, blood corpuscles and things of that sort, but not ideas. Spatial predicates are not applicable to them: an idea is neither 
to the right nor to the left of another idea; we cannot give distances between ideas in millimetres. If we still say they are within us, then we intend by this to signify that they are subjective.

Yet even granted that what is subjective has no position in space, how is it possible for the number 4, which is objective, not to be anywhere? Now I contend that there is no contradiction in this whatever. It is a fact that the number 4 is exactly the same for everyone who deals with it; but that has nothing to do with being spatial. Not every objective object has a place. (Frege, 1884 \61)

In the text just quoted, Frege implies that the pair of concepts internal vs. external, even when applied to ideas, has to be understood metaphorically. Neither ideas nor concepts are within us; they are not anywhere. Ideas, numbers and other concepts lack spatial properties altogether. Applying spatial predicates to them is to commit a category mistake, in Ryle's sense $(1949 / 2009$, p. 8ff.). Metaphysical realism is thus the realm in which this category mistake is taken to its limits.

The objectivity of mathematics against psychologism is Frege's main concern. The first principle that guides his work on numbers is explicit: "always to separate sharply the psychological from the logical, the subjective from the objective" (Austin's translation, 1884, p. xxii). The essence of psychologism is the dependence of concepts on the individual mind. Psychologism at this point runs against our intuition, since even though the number four is not a physical object, it does not belong to anybody either. Frege's response to the apparent paradox was to show that the dichotomy subjective vs. located is not exhaustive. To be objective, contents do not need to be located somewhere. Concepts, in general, and numbers, in particular, are neither subjective nor located. And they are nevertheless objective, their objectivity lying in the independence of their properties and relations from our will:

That a statement of number should express something factual independent of our way of regarding things can surprise only those who think a concept is something subjective like an idea. But this is a mistaken view. If, for example, we bring the concept of body under that of what has weight, or the concept of whale under that of mammal, we are asserting something objective $(1884, \S$ 47$, p. 60$)$ 

instantiated:

And they certainly exist, their existence meaning their being

Existence is analogous to numbers. In this respect existence is analogous to number. Affirmation of existence is in fact nothing but denial of the number nought. $(1884, \S 53$, p. 65$)$

Existence, for Frege, is a property of concepts, i.e. a higher-order concept. Spatial predicates, on the other hand, encode properties of physical objects, i.e. first-order concepts. We say that Joan's mobile phone is in the car and that the North Star is in Ursa Minor. Nevertheless, when we claim that there are left-wing Europeans, we are not predicating anything of any localized European citizen, we are predicating something of the concept "left-wing European": that is not empty. Higher-order concepts (such as truth, existence, knowledge) apply to other concepts, including propositions. By definition, their arguments do not have spatiotemporal localization, and thus higher-order concepts do not represent features or elements of situations or state-of-affairs. Even if we insisted on sticking to the representationalist view of meaning concerning names and first-order predicables, there are still reasons not to follow the same path concerning higher-order concepts. For representationalists, the sentence "the cat is on the mat" is able to describe any situation in which the ingredients include a cat, a mat, and the relation of being on (the cat, the mat), and "the dog is under the tree" is able to describe any situation with dog, a tree, and the relation of being under (the dog, the tree). But surely the type-situation that could be represented by the sentence "The cat is on the mat and the dog is under the tree" would not include more elements that the sum of the two type-situations related to each of its conjuncts. Conjunction is not an ingredient of situations, and the same is the case with reference and truth. The type-situations that representationalism relate with "That the cat is on the mat is true" and with "There is a cat on a mat" surely share all their ingredients with the type situation depicted by "The cat is on the mat". Similarly, saying that "the cat" refers to the cat in a particular situation does not add a new component to the situation at hand. Reference, truth, fact, and also knowledge, belief, and any other higher order notions cannot be reduced to physical objects and properties. Their meaning is 
seen in the functions they perform. Let us consider a few examples to clarify the point:

[13] The analysis of the materials picked up on Mars in the latest NASA mission detects unequivocal traits of $\mathrm{H}_{2} \mathrm{O}$ of extra-terrestrial origin.

[14] The cardinality of the set of real numbers is greater than the cardinality of the set of natural numbers.

[15] To prepare Peking duck, you have to be an expert cook.

Whoever sincerely asserts [13], becomes thereby committed to [16],

[16] There is (or has been) water on Mars.

If a speaker claimed [13] and at the same time rejected [16], we would be entitled to doubt the speaker's understanding of the notions involved.

By the same argument, whoever claimed [14] would have to accept [17],

[17] There are transfinite numbers greater than $\aleph_{0}$.

Again, if somebody asserted [15] and in the same act rejected [18],

[18] There are ways of preparing duck not apt for beginners,

we would be entitled to accuse the person of pragmatic inconsistency.

Do these inferences force us to assume water, transfinite numbers, and ways of preparing duck as primitive objects in the physical universe? The Fregean analysis of existence shows that they do not. A quite standard reaction to the question that starts this paragraph is that the three inferences are of a very different nature - that is, that the assertion of [13] commits us to accepting the existence of water, but that this is not so in the other two cases. This answer is misleading, and the recourse to the idea of a canonic language in which ontological commitments are perspicuous and/or to the procedure of rephrasing - the standard Quinean answers - is begging the question. To give an appropriate explanation, two aspects should be distinguished: the first one 
has to do with the inferential connections between these three pairs of propositions, [13] to [16], [14] to [17], and [15] to [18]. The rule of existential generalization, the rule that supports the transitions from [13], [14], and [15] to [16], [17], and [18], respectively, is an essential feature of the semantic behaviour of the concept of existence. Existence, as a higher-order notion, expresses some property of concepts, in this case that they are not empty. By [13], we say that the concept "Martian water" is not empty, by [14] we say the concept "transfinite number greater than $\aleph_{0}$ " is not empty and by [15] we say that the concept "a novice cook capable of preparing Peking duck" is empty. The further inference that, in order to assert existence, some kind of causal connection to "reality" should be established is tantamount to requiring that extensions of concepts always consist of physical objects. Reductionist object naturalism regards all concepts as first-order concepts encoding physical properties.

The second aspect is related to the circumstances under which we are entitled to assert [13]-[10]. To be in a position to assert [16], we should have some kind of causal link, even if indirect, to samples of $\mathrm{H}_{2} \mathrm{O}$. The required connection is provided by the assertion circumstances of [13]. However, the requirement of the causal link is independent of the meaning of existence; it depends on the empirical status of the kind of discourse to which [13] belongs. Nevertheless, conceptual instantiation takes place in any kind of discourse, regardless of its subject matter. Properties of physical objects are instantiated by physical objects, whereas properties of abstract objects are instantiated by abstract objects. The inferential import of the existential higher-order concept forces us to accept [17] when we accept [14], and to accept [18] when we accept [15]. Otherwise our use of the notions involved would be sui-generis.

The differences between [13], [14], and [15] rest on the different assertion criteria fitting the kind of discourse to which they belong. To assert [14] we should have some kind of proof. But once we have it, if the proof supports our assertion of [14], it necessarily has to support our assertion of [17]. The kinds of criteria that entitle us to assert [14] are not the kinds of criteria on which we rely in order to assert [15]. Be that as it may, however, once we are entitled to assert [15], we have all we need to assert [18].

Placement problems make sense related to the instantiation of firstorder concepts on physical objects. Its extension to cover any kind of concept is a reductionist move that finds no support in our best theoretical treatment of existence, which is the Fregean account. 
Non-reductionist object naturalism, the theoretical position that includes philosophy in the web of knowledge, and subject naturalism, the attitude that interprets humans as part of the natural world, are nonreductionist positions robust enough to support a theoretical treatment of the concepts we use. Subject naturalism also explains the powerful intuitions behind default realism, default representationalism, and default correspondentism. Animals as we are, our nature entitles us to master language in all its breath, including abstract discourse on non-physical entities and higher-order concepts.

Maria José Frápolli

University of Granada/University College London

mifrapolli@gmail.com

\section{REFERENCES}

Austin, J. (1950/2013), "Truth". Proceedings of the Aristotelian Society. The virtual issue, $\mathrm{n}^{\circ} 1$, pp. 1-15.

Barwise, J. \& Perry, J. (1983), Situation and Attitudes. Cambridge, Mass., London, England, The MIT Press.

Benacerraf, P. (1973), "Mathematical Truth", The Journal of Philosophy, vol. LXX, no 19, 661-679.

Brandom, R. (2000), Articulating Reasons. An introduction to inferentialism. Harvard University Press

FrÁpolLI, M.J. (2013), The Nature of Truth. An updated approach to the meaning of truth ascriptions. Logic, Epistemology and the Unity of Science, vol. 29. Springer.

FrÁpolLI, M.J, (in press), "No Miracles. What does it mean that science seeks the truth?", Zagadnienia Naukoznawstwa.

Frege, G. (1884/1980), The Foundations of Arithmetic. A logico-mathematical enquiry into the concept of number, Oxford, Basil Blackwell.

HAACK, S. (2007), "The same only different: integrating the intentional", in Haack, S. (2007), Defending Science Within Reason. Prometheus Book

HAACK, S. (2009), Evidence and Inquiry. A pragmatist reconstruction of epistemology. Prometheus Book

Horwich, P. (1998), Truth, Oxford University Press. 
PeIrCe (1868a), "Questions Concerning Certain Faculties Claimed for Man", Journal of Speculative Philosophy, 2, (1868), pp. 103-114.

PeIRCE (1868b), "Some Consequences of Four Incapacities", Journal of Speculative Philosophy, 2, (1868), pp. 140-157.

http://www.peirce.org/writings/p27.html

PRICE, H. (2004) "Naturalism without representationalism", in Mario de Caro and David McArthur (eds.), Naturalism in Question, Harvard University Press, pp. 71-88.

Price, H. (2011), Naturalism without Mirrors, Oxford University Press.

Quine, W. (1981), "Five Milestones of Empiricism", in Theories and Things. Cambridge: Harvard University Press.

RAMSEY, F.P. (1927/1991), "The nature of truth", in N. Rescher and U. Majer (eds.), On Truth: Original manuscript materials (1927-1929) from the Ramsey collection at the University of Pittsburgh, Dordrecht: Kluwer Academic, pp. 6-16.

Recanati, F. (2010), Truth-Conditional Pragmatics, Oxford University Press. RYLE, G. (1949/2009), The Concept of Mind, London and New York, Routledge.

Strawson, P. F. (1950/2013), "Truth", Proceedings of the Aristotelian Society. The virtual issue, $\mathrm{n}^{\circ} 1$, pp. 1-22.

TARSKI, A. (1944), "The semantic conception of truth and the foundations of semantics", Philosophy and Phenomenological Research, IV, pp. 52-84.

Williams, C.J.F. (1992), Being, Identity and Truth, Oxford: Clarendon Press.

WitTgenstein, L. (1953), Philosophical Investigations, Blackwell Publishing.

Wittgenstein, L (1969), On Certainty, Oxford, Basil Blackwell. 